Anuario Latinoamericano

Ciencias Políticas

y Relaciones Internacionales

vol. 1, 2014

p. $25-44$

\title{
Las políticas públicas de memoria y la integración latinoamericana: el Grupo Bicentenario
}

\author{
Georg T. A. Krizmanics \\ INSTITUTO UNIVERSITARIO DE INVESTIGACIÓN \\ ORTEGA Y GASSET, MADRID, ESPAÑA \\ $\triangle$ georg.krizmanics@sciences-po.org
}

\begin{abstract}
RESUMEN
¿Qué impacto tuvieron las políticas públicas de memoria en torno a las conmemoraciones bicentenarias del inicio de las Independencias en América Latina en la integración latinoamericana? Para el estudio de esta cuestión el trabajo se centra en el análisis de las actividades del Grupo Bicentenario que fue creado para promover la conmemoración conjunta del inicio de los movimientos de independencia en América Latina. ¿Cuáles fueron los objetivos del Grupo Bicentenario? ¿Llegó a alcanzarlos? ¿Qué impacto tuvieron las actividades del Grupo en la integración latinoamericana? ¿Qué narrativa histórica fue propagada por el Grupo? ¿Cuál es el proyecto identitario detrás de la integración latinoamericana?
\end{abstract}

PALABRAS CLAVE: políticas públicas de memoria, bicentenarios, integración latinoamericana, Grupo Bicentenario.

\section{SUMMARY}

What was the impact of the politics of public memory, concerning the commemorations of the bicentenaries of the beginning of the independence movements in Latin America in the context of Latin American integration? For the study of this question, the paper is focused on the analysis of the Bicentenary Group activities. The group was created to promote the joint commemorations of the beginning of the independence movements in Latin America. What were the group's objectives? Did the group achieve them? What was the impact of the group's activities on Latin American integration? What historical narrative has been propagated by the Group? What is the identity project behind Latin American integration?

KEYWORDS: politics of public memory, bicentenaries, Latin American integration, Bicentenary Group. 
América Latina: cambios a nivel regional y en su inserción internacional

\section{Los vaivenes de la integración}

Los jefes de Estado y de Gobierno latinoamericanos no paran de poner en escena nuevos mecanismos de integración que se presentan una y otra vez como la panacea para conseguir la integración política, económica y social anhelada sobre todo retóricamente - desde hace mucho tiempo; algunos dirían que desde hace 200 años. La referencia al llamado sueño de Bolívar rara vez falta en los actos solemnes de inauguración de un nuevo mecanismo de integración. Una de las últimas pruebas en este sentido fue la cumbre fundacional de la Comunidad de Estados Latinoamericanos y del Caribe (CELAC), celebrada del dos a tres de diciembre de 2011 en Caracas. ${ }^{1}$ Este proceder no beneficia la consolidación de la integración, sino bien al contrario, la vuelve difusa. Al parecer, los jefes de Estado y de Gobierno se preocupan cada vez más por crear capital político a corto plazo mediante los discursos en estos actos solemnes con el objetivo de mejorar su imagen mediática personal. Ya se puede hablar de una estrategia, por parte de los responsables políticos, que consiste en la búsqueda de no enfrentar y conscientemente evitar los problemas que se presentan a la hora de poner en práctica los mecanismos de integración. Que las modalidades descritas perduran evidencia el preludio al segundo paso para consolidar la definición de la CELAC que se iba a dar del cinco al seis de julio de 2011 en Venezuela. El entonces canciller de Venezuela, Nicolás Maduro, advirtió con franqueza que el escenario que se estaba preparando no estaba sola y únicamente dedicado a cuestiones de la CELAC: "Aquí en Venezuela tenemos que terminar de consolidar [...la definición del concepto de la CELAC...] y precisamente se hará en momentos de la celebración de nuestro pueblo y de toda América Latina en los 200 años de la declaración de independencia de Venezuela [el cinco de julio, el autor]" (Rodríguez 2011: párr. 1). Cabe resaltar que, por problemas de salud del presidente venezolano, Hugo Chávez, se aplazó esta reunión; los homenajes del bicentenario, sin embargo, se llevaron a cabo y contaron con la presencia aunque limitada - del presidente. ${ }^{2}$ Esto ejemplifica la tendencia prevaleciente de perseguir los intereses nacionales en contextos bi o multilaterales sin asumir "los peajes de la unidad" (Sotillo 2010: 13). Este hecho forma parte de lo que más ampliamente se puede llamar un "déficit de liderazgo" (Maladmud 2009: 104-108) en el ámbito de la integración latinoamericana.

1 Camino que se emprende por la llamada "Cumbre de la Unidad", cuyo nombre deriva de la celebración conjunta de la XXI Cumbre del Grupo de Río y la II Cumbre de América Latina y el Caribe sobre Integración y Desarrollo (CALC) en febrero de 2010 en México. Para los documentos de la "Cumbre de la Unidad" véase: http://www.sre.gob.mx/cumbredelaunidad/ default.htm, consulta: 31.01.2013; acerca del proceso fundacional y los documentos oficiales de la CELAC véase: http://www.gob.cl/cumbres/celac/, consulta: 31.01.2013.

2 Véase el comunicado de la cancelación de la III CALC por el Ministerio del Poder Popular para Relaciones Exteriores de la República Bolivariana de Venezuela (2011) y la nota de la Prensa Presidencial (2011) sobre la participación del presidente Chávez en los actos del bicentenario. 
En este trabajo me intereso por el impacto que tuvieron en la integración latinoamericana las políticas públicas de memoria en torno a las conmemoraciones bicentenarias del inicio de las Independencias en América Latina. Como objeto de análisis me centraré en el Grupo Bicentenario ${ }^{3}$ que se constituyó en 2007 en el ámbito de la Comunidad Iberoamericana de Naciones. La importancia de este grupo también fue reconocida en otros sistemas de integración, como veremos a continuación. Mi análisis abarca los años de la existencia del grupo desde 2007 hasta 2012. Trabajé utilizando un enfoque de análisis crítico de discurso. El corpus abarca las actas publicadas en la página web del propio Grupo Bicentenario. ${ }^{4}$ Paralelamente, incluí en el análisis aquellos documentos de otros mecanismos o sistemas de integración que hacen referencia al Grupo Bicentenario. Especialmente interesante resultó la comparación del Grupo Bicentenario con el Grupo ALBA para la Conmemoración del Bicentenario del Inicio de la Revolución de Independencia en Nuestra América. Este último fue creado por el gobierno de Hugo Chávez y sus gobiernos aliados agrupados en el ALBA el 24 de junio de 2009 para contrarrestar al Grupo Bicentenario y sus actividades. Hasta ahora, son muy pocos los estudios dedicados a la investigación de la integración latinoamericana desde un punto de vista de políticas públicas de memoria. Prevalecen los estudios que tratan de explicar los altibajos de la integración latinoamericana con un enfoque económico o sistémico-institucional. Sin poner en duda su utilidad y necesidad, hay dinámicas que no se explican mediante estos análisis, por ejemplo, el origen de muchas diferencias y divergencias en la región se encuentra, desde hace aproximadamente una década cada vez más, en cuestiones ideológicas, las cuales no solamente determinan la imaginación del futuro y las actuaciones en el presente, sino también la (re) construcción del pasado.

Con este trabajo, analizando la integración latinoamericana desde un enfoque de políticas públicas de memoria, pretendo aportar conclusiones innovadoras y espero enriquecer así el debate actual al respecto. A continuación desarrollo qué es lo que comprendo bajo políticas públicas en el contexto de la integración latinoamericana, partiendo de la importancia de la retórica. Importante en este contexto también es la idea de independencia que rige en la región, sobre la cual reflexionaré a continuación. Después me centraré en el análisis de las actividades del Grupo Bicentenario. A base del mismo terminaré con la presentación de algunas reflexiones sobre la percepción ciudadana de las conmemoraciones bicentenarias, seguido por conclusiones finales.

3 El grupo se constituye por 9 miembros hispanoamericanos (Argentina, Bolivia, Chile, Colombia, Ecuador, El Salvador, México, Paraguay y Venezuela) y España (Grupo Bicentenario 2007; 2007a).

4 La página del grupo http://www.grupobicentenario.org dejó de funcionar por completo hacia finales de 2012.
Las políticas públicas de memoria y la integración latinoamericana: el Grupo Bicentenario

Georg T. A. Krizmanics 
América Latina: cambios a nivel regional y en su inserción internacional

\section{Retórica como herramienta de integración}

Señalé que la retórica no comprometedora es una característica que destaca cuando se observa la integración regional latinoamericana y caribeña. Los que utilizan esta retórica se inspiran en los conceptos de unidad territorial y política propagados por Bolívar a lo largo de su lucha por la independencia de las colonias latinoamericanas y caribeñas. El fracaso de Bolívar, sin embargo, no significa la desaparición de su concepción de unidad, bien al contrario, hoy en día parece más presente que nunca mediante la metáfora del sueño de Bolívar. No obstante, esta metáfora mantiene en la actualidad una conexión rudimentaria con el ideario originario creado por Bolívar, expresando más bien las esperanzas por un futuro mejor, verdaderamente independiente, alcanzable solamente mediante un modo de proceder unitario y coordinado. La exaltación retórica produce, ante todo, una construcción imaginaria de integración regional, cuyo progreso de integración se simula por medio de un discurso cada vez más extremo. En consecuencia, el discurso sobre la integración regional se degrada principalmente a un ejercicio político-ideológico (Malamud 2008), que según algunos analistas encabezaba el presidente venezolano Hugo Chávez, bien como líder ideológico de un nuevo modelo de integración, bien como el origen de todo el mal (Gudynas 2006: 16 y s.).

Así, la legitimidad de un modelo regional de integración depende crucialmente de la referencia al llamado sueño de Bolívar. Éste, influenciado por conceptos ilustrados en torno a la libertad, igualdad y fraternidad es, en primer lugar, de importancia nacional. Su significado destaca particularmente en la región andina siendo un elemento primordial de la identidad nacional. ${ }^{5}$ Como pieza clave de los nacionalismos de esta región, este sueño representa el mito fundador de estas naciones, cuyos mecanismos elucidan Wodak y de Cillia (2007). Hablando en general, todas las sociedades pueden hacer referencia a experiencias traumáticas vividas en su pasado (Wodak y de Cillia 2007: 338) que en toda regla forma la base de la construcción de una narrativa fundadora. Aunque ésta difiere de un país a otro en América Latina y el Caribe, se puede observar que hay una especie de concordancia referente al origen histórico común entre estos países; de manera que en el documento final de la primera Cumbre de América Latina y el Caribe sobre Integración y Desarrollo (CALC), que tuvo lugar en 2008, ya el punto 2 remite a la "convicción de que la integración política, económica, social y cultural de América Latina y el Caribe es una aspiración histórica de sus pueblos". ${ }^{6}$ Una referencia en concreto a esta aspiración histórica da el punto 19, donde se felicita al Grupo Bicentenario por sus acciones que "viene realizando en pos del reconocimiento y la valoración de los aspectos comunes de las gestas independistas de los

\footnotetext{
5 Para el caso de Venezuela véase, por ejemplo, Harwich (2003) y Zeuske (2009).

6 Véase punto 2 de la Declaración de Salvador, Bahía. Referencia a este concepto también hacen Altmann/Rojas Aravena (2008, XIII y s.) y García-Belaunde (2000).
} 
países de América Latina y el Caribe." Además, se resalta que "estas acciones contribuyen a generar conciencia acerca del pasado compartido por pueblos de las Américas y a fomentar la proyección de un futuro que los encuentre integrados en la diversidad."

\section{Políticas públicas de memoria e integración}

Esta alusión presume la influencia importante, incluso la posición hegemónica, de una versión hispanoamericana de la historia en el marco de la integración latinoamericana y caribeña. ${ }^{8}$ El poder de definición en este discurso parece estar, ante todo, en manos de los miembros del Grupo Bicentenario. En su sitio web, el grupo se describe como una "instancia multilateral creada con el objetivo de promover la conmemoración conjunta de los procesos de independencia desarrollados en el continente americano hace 200 años". En cuatro de los diez países participantes - Bolivia, Colombia, Ecuador y Venezuela - la figura de Simón Bolívar forma parte del santuario nacional.

A pesar de que la relevancia histórica de Bolívar para Brasil, México, Uruguay, Paraguay, Chile, Argentina y los Estados centroamericanos y caribeños sea menos aparente, hay que tener en cuenta que las vidas de los héroes de la independencia de estos países sí tienen en toda regla puntos de contacto con la vida de Bolívar (Palacios et al. 2003; Pimenta 2007; Rinke 2010). La importancia histórica del Libertador más allá de Sudamérica se manifiesta, por ejemplo, para Nicaragua con el "Plan de Realización del Supremo Sueño de Bolívar” redactado por Sandino (1982 [1929]). También por este hecho se explican las afinidades del gobierno actual nicaragüense (sandinista), bajo Ortega, con el proyecto bolivariano y el ALBA. Asimismo, se confirmó la influencia del ideario de Simón Bolívar en el pensamiento de José Martí (Lamore 2007: 75-102), cuya obra de nuevo fue central para el ideario de la Revolución Cubana bajo el liderazgo de Fidel Castro (compárese: Ramonet 2008: 164), lo que entre otras cosas explica la cercanía ideológica entre los líderes venezolanos y cubanos. Hugo Chávez se empeñó desde el principio de su proyecto bolivariano en establecer a Simón Bolívar como la conexión ideológica entre los movimientos de independencia, de manera que llegó a ser "una especie de protomártir de la integración latinoamericana." (Malamud 2008: párr. 3) En esto se le puede ver "como metáfora para las preguntas que quedaron sin responder durante los últimos dos siglos y como invitación para hablar de la empresa inconclusa de una América La-

\footnotetext{
7 Véase punto 19 de la Declaración de Salvador, Bahía.

8 El concepto de Hispanoamérica se utiliza aquí solamente en términos analíticos refiriéndose a los Estados latinoamericanos con español como idioma oficial. El autor es consciente de la problemática subyacente a este término en el contexto latinoamericano, ya que su trayectoria etimológica nace durante el periodo colonial. El concepto de identidad que se asocia al mismo estaba/está determinado primordialmente por actores desde España.
}

Las políticas públicas de memoria y la integración latinoamericana: el Grupo Bicentenario

Georg T. A. Krizmanics 
América Latina: cambios a nivel regional y en su inserción internacional tina moderna en el siglo XXI." (Conway, citado en Gabbert 2008: 164) Además, la mención a Bolívar permite representar un proyecto de integración como "genuinamente latinoamericano" (Boeckh 2005: 75).

En la figura de Simón Bolívar se representan, por lo tanto, significados regionales del pasado, presente y futuro latinoamericano que de manera confusa e inconcreta también incluyen a los Estados caribeños. Asimismo, Bolívar es estilizado como elemento esencial de identificación regional. Esto se manifiesta, por ejemplo, en el discurso del presidente mexicano, Felipe Calderón, en la ceremonia de entrega de la Secretaría Pro Témpore del Grupo de Río, en 2008, a este país, citando a Alfonso Reyes que señaló que el "mejor tributo que podemos ofrecer a la memoria de Bolívar, de San Martín, de Hidalgo, de todos los creadores de la Independencia Americana, es trabajar en el porvenir de nuestros pueblos. Lo que vosotros intentéis lo continuarán vuestros hijos y lo realizarán vuestros nietos. Me parece oír sus bendiciones. Para eso habremos luchado." (Calderón Hinojosa 2010: último párr.)

Entre el abanico de las estrategias políticas, las políticas de memoria son esenciales para generar identificación y legitimación política. Sirviéndose de la historia, los actores políticos pueden crear referencias conjuntas, capaces de unir grupos anteriormente difusos alrededor de un proyecto de sociedad. Al mismo tiempo, el concepto de políticas de memoria también constituye una herramienta analítica importante que permite identificar, justamente, la instrumentalización política de la historia, entender su finalidad y las circunstancias de su construcción y descifrar su virulencia en el contexto político del presente. En esta concepción amplia, las políticas públicas de memoria son entendidas como subcategoría de las políticas de memoria (Sandner 2001: 7).

¿De qué clase de independencia hablan los líderes políticos de la región y qué concepto de independencia persiguen realmente? ¿Cuáles son las implicaciones para la integración? El representante chileno en la V Reunión del Grupo Bicentenario realizada en la Ciudad de Guanajuato, México, el 28 de septiembre de 2009, habla de "celebrar y conmemorar los 200 años de vida republicana" y, por tanto, de 200 años de independencia (Grupo Bicentenario 2009). Un enuncio, por cierto, que puede llevar a equívocos, ya que los sucesos históricos que transcurrieron entre 1809 y 1811 se deberían entender más bien como los comienzos de los procesos que desembocaron en las independencias políticas de los Estados latinoamericanos y no como el logro de la independencia en sí misma. Dirigiendo la mirada hacia América Latina en su conjunto, podemos observar un proceso que engloba un periodo de conmemoraciones de aproximadamente 16 años. Empieza a partir de 2009, con la conmemoración de los primeros gritos de independencia, y termina entre 2021 y 2025 con las conmemoraciones de la consumición de las independencias. Las declaraciones de independencia en los diferentes territorios latinoamericanos deberían leerse pensando en el contexto de su proclamación. De modo que en su momento eran, ante todo, una declaración de inten- 
ciones para construir un Estado-nación en un territorio más o menos definido y a partir de las herencias coloniales.

También es de esperar que el año 2030, en el que se celebrará el 200 aniversario de la muerte de Simón Bolívar, tenga una importancia supraregional en el contexto de las conmemoraciones bicentenarias. Frente a este período largo de introspección histórica y el hecho de que con este año 2011 terminará el primer bloque de las conmemoraciones bicentenarias, parece oportuno plantearse la pregunta del impacto de los bicentenarios en las políticas de la integración regional. En fin, la construcción de un futuro común depende también de la base histórica sobre la cual éste se erige, por lo que los bicentenarios podrían ser el motivo para trabajar una historia supraregional respaldando el proyecto político de integración.

La meta de la Alternativa Bolivariana para los Pueblos de Nuestra América (ALBA) y actual Alianza Bolivariana para los Pueblos de Nuestra América - Tratado de Comercio de los Pueblos (ALBA-TCP) se define en el documento fundacional de este sistema de integración, donde consta que "con la consolidación de la Revolución Bolivariana y el fracaso indiscutible de las políticas neoliberales impuestas a nuestros países, los pueblos latinoamericanos y caribeños se encuentran en el camino de su segunda y verdadera independencia." (ALBA 2004: último párr.) Este objetivo de la segunda y verdadera independencia precede de hecho, pero bajo otros términos, a las primeras declaraciones de independencia en el subcontinente americano. Tiene su origen en el pensamiento de Francisco de Miranda que diferenció entre independencia política y emancipación mental (Roig 2007: 30). Lo primero se alcanzó en el transcurso de la primera mitad del siglo XIX. La emancipación mental, en cambio, va mucho más allá de una victoria militar o "un cambio de formas", ya que requiere "el cambio de espíritu" (Martí 2005c [1891]: 35). La emancipación mental parece ser, por lo tanto, un concepto normativo, ante todo un Leitmotiv que no debería entenderse como meta plenamente alcanzable, como sí lo tienden a hacer Chávez y sus homólogos aliados. ¿Es posible una independencia plena, es posible una democracia plena? Tanto independencia como democracia no son bienes que se puedan poseer, sino el resultado temporal en el día a día de las negociaciones que definen las relaciones y proporciones de poder. La independencia fijada en un papel, en una declaración de independencia, hace creer demasiado fácilmente que el logro es igual a una toma de posesión de la misma. Esto, sin embargo, no es más que una ilusión a la que también Bolívar hizo referencia en su Discurso de Angostura cuando dijo que "[n]uestras manos ya están libres, y todavía nuestros corazones padecen de las dolencias de la servidumbre." (2008 [1819]: 40 y s.) A pesar del corte nítido que la independencia política significó en el papel, "la constitución jerárquica de las colonias resistía la organización democrática de la República” (Martí 2005c [1891]: 35).

Resistencia significativa por parte de las antiguas y nuevas élites que por miedo de cambios sociales profundos hicieron todo para que nocio-
Las políticas públicas de memoria y la integración latinoamericana: el Grupo Bicentenario

Georg T. A. Krizmanics 
América Latina: cambios a nivel regional y en su inserción internacional nes como nación o pueblo, es decir, la caracterización del nuevo soberano a constituir, se quedase lo suficientemente imprecisa y que se aplicaran definiciones según su conveniencia. Utilizaron una retorica de valores universales que no tuvo implicaciones reales en contra de las prácticas dominantes de discriminación social (Rinke 2010: 300). La composición heterogénea de las sociedades con la inherente fuerza explosiva social representó desde el punto de vista de la alta sociedad una amenaza interna que le causó un malestar parecido al provocado por las amenazas externas. La esclavitud, que después de las guerras de independencia perdió su legitimación como mecanismo de control para la conservación de las divisiones étnico-sociales, fue compensada por medidas socio y económico-políticas y limitaciones en el derecho electoral, de manera que persistieron las desigualdades económicas, étnicas y sociales (Rinke 2010: 303 y s.). Bien es verdad que los movimientos de independencia se deshicieron de los lazos que les unieron a la corona española, pero también tenían que enfrentar el aumento en los niveles de fragmentación del, hasta entonces, reivindicado monopolio del uso legítimo de la violencia física por parte de la corona. Aunque su monopolio no haya sido absoluto sí defendía con éxito la reivindicación del mismo. En palabras de Pierre Bourdieu (1993: 51), que modifica una definición de Max Weber, el Estado "reivindica con éxito el uso legítimo de la violencia física y simbólica sobre un territorio y sobre el conjunto de su población." El precio a pagar para poder imponer esta reivindicación con éxito fueron las mencionadas guerras de independencias, las guerras civiles y las guerras entre las emergentes repúblicas. "Ello elevó a niveles casi insoportables el peso de los ejércitos en los presupuestos del Estado" (Garavaglia 2003, 135). Los Estados, debilitados por el precio de la libertad (Rinke 2010: 289-315), no tenían fuerzas suficientes para oponerse al establecimiento de nuevas dependencias a lo largo del siglo XIX, es por eso que Gustavo Beyhaut habla al respecto también de la Segunda Conquista (Kaller-Dietrich 2006: 125), con la que América Latina fue incluida como suministrador de productos primarios al mercado mundial (Kaller-Dietrich 2006: 139).

Las promesas hechas por Bolívar y sus combatientes en cuanto a la realización de estructuras sociales igualitarias quedaron sin cumplir, sin embargo, las ideas libertarias, igualitarias y de autodeterminación dejaron una sociedad politizada, lo que puede denominarse como promesa de la Revolución (Rinke 2010: 314 y s.). Comprometido con esta promesa estuvo José Martí, como se esbozó arriba, que estaba convencido de que "la última estrofa del poema de 1810" (2005a [1889]: 23) todavía quedaba por escribir y, a pesar de la ausencia física del Libertador, Martí, impresionado por su ideario, estaba convencido de que "[j...] lo que él no dejó hecho, sin hacer está hasta hoy: porque Bolívar tiene que hacer en América todavía!” (2005d [1893]: 237) A esta última estrofa, para utilizar los términos de Martí, éste le reservó como título segunda independencia (2005b [1889]: 57). El poeta cubano concluye que, después de que la primera independencia hubiera resultado en nuevas dependencias, habría 
que trabajar en la declaración de la segunda. Especialmente, los cambios en las políticas exteriores de EEUU bajo la presidencia de James A. Garfield y su secretario de Estado, James G. Blaine, a partir de 1881, convencieron a Martí de la necesidad de la empresa de la segunda independencia. El cambio en las políticas estadounidenses se manifestó en la reinterpretación de la Doctrina Monroe, elaborada bajo la responsabilidad de Blaine, lo que conllevó una política agresiva frente a las repúblicas centro y sudamericanas y del Caribe (Lamore 2008: 90). Desde que Martí la introdujo, la terminología segunda independencia permaneció, a veces más, otras menos, como un elemento clave en el discurso político latinoamericano. Con el llamado giro a la izquierda, a partir de 1998, cuando Chávez ganó las elecciones presidenciales en Venezuela, se observa una especie de renacimiento del concepto que se manifiesta de manera especialmente pronunciada en el ámbito de los Estados miembros del ALBA. Tanto antes como hoy se trata de defender la promesa de la Revolución, como lo evidencia la comparación de ejemplos entre el discurso político del pasado y de la actualidad.

Esta es la hora, digo, en que los sueños de independencia de nuestros países están en peligro y hay que levantar la voz antes de que de todo ello solo quede un recuerdo esfumado ante las hoscas realidades, que nos atan económicamente a los grandes núcleos dueños del mercado mundial o políticamente a las naciones caudillos que dominan el escenario del mundo. (Ugarte 1922: 127 y s.)

Apenas cien años más tarde, las inquietudes se parecen, siguen sin grandes diferencias, como demuestra el documento final de la IX Cumbre de los países miembros del ALBA-TCP (2010) y la declaración para la creación de este sistema (2004). En el documento de constitución se afirma que el principio fundamental que debe guiar al ALBA “es la solidaridad más amplia entre los pueblos de América Latina y el Caribe, que se sustenta con el pensamiento de Bolívar, Martí, Sucre, O’Higgins, San Martín, Hidalgo, Petión, Morazán, Sandino, y tantos otros próceres, sin nacionalismos egoístas ni políticas nacionales objetivas que nieguen el objetivo de construir una Patria Grande en la América Latina, según lo soñaron los héroes de nuestras luchas emancipadoras." (ALBA 2004: párr. 7) Sigue "la lucha de los pueblos por alcanzar la definitiva independencia, con justicia plena, libres del intervencionismo extranjero, sin sumisión a mandatos imperiales" (2010: párr. 3), como se asegura en el documento final de la IX Cumbre intitulado Manifiesto Bicentenario de Caracas.

Tanto las conmemoraciones del V Centenario del llamado "Descubrimiento de América", como las conmemoraciones de los bicentenarios han demostrado que los temas de integración pasan por cuestiones identidarias. Las preguntas que siempre surgen en estas ocasiones son las de ¿quiénes somos, qué es lo que nos une, cómo nos representamos? La reflexión sobre los oríge-
Las políticas públicas de memoria y la integración latinoamericana: el Grupo Bicentenario

Georg T. A. Krizmanics 
América Latina: cambios a nivel regional y en su inserción internacional nes individuales y colectivos es equivalente a la búsqueda causal del sentido del ser. Por este motivo, la memoria no es otra cosa que la reflexión de uno sobre sí mismo, extendido en el tiempo (Ricœr 2000: 734).9

Sin embargo, lo que une a unos, también puede separarles de otros. Son preguntas difíciles y pueden tener implicaciones problemáticas. Entonces, si ya a nivel nacional es complicado dar una respuesta a esas preguntas, ¿cómo se manejan estas cuestiones en la integración regional? Al fin y al cabo, los motivos a los que se alega a la hora de propulsar un proceso de integración son los intereses compartidos fundamentados en raíces comunes. La respuesta hasta ahora más repetida con aire de fórmula mágica es la de la integración en la diversidad. Se construyen las identidades nacionales y regionales, como la andina, sudamericana, centroamericana, caribeña, latinoamericana e iberoamericana, sin que apenas haya mecanismos de integración sin su propio proyecto identitario. Así lo ejemplifica un párrafo en el preámbulo del Tratado Constitutivo de la Unión de Naciones Suramericanas, donde afirman las partes signatarias "su determinación de construir una identidad y ciudadanía suramericanas" (UNASUR 2008: Preámbulo párr. 3) Estos proyectos están ligados a espacios con delimitaciones más o menos arbitrarias y más o menos definidas. En todo caso, las demarcaciones se argumentan según criterios geográficos, culturales, políticos, históricos, económicos y sociales. ¿Cuán grande es realmente la determinación de construir una identidad fuera de contextos nacionales? ¿Quién tiene interés en construirla y bajo que términos? ¿Cuáles son las complicaciones que pueden surgir para los procesos de integración teniendo en cuenta los múltiples proyectos de construcción identitarios, es decir, proyectos de diferenciación?

\section{¿Qué pasó con el Grupo Bicentenario?}

En la "Carta de intención de los ministros de cultura relativa a la realización de actividades conjuntas para la conmemoración de los bicentenarios", firmada el 26 de julio de 2007 por los representantes de Argentina, Bolivia, Chile, Ecuador, México, Paraguay y Venezuela, reunidos en el marco de la XXII Cumbre Iberoamericana, ellos manifiestan su intención de:

1. Apoyar a la entidad que se ocupará de la conmemoración del Bicentenario en cada uno de sus países. [...]. 2. Construir una Mesa de Trabajo multilateral [...]. 3. Reunirse dos veces al año en sesiones ordinarias [...]. 4. Cuando lo estimen oportuno podrán celebrar reuniones extraordinarias. 5. Que las decisiones de la Mesa de Trabajo sean adoptadas por consenso. 6. Que la mesa de trabajo tenga los siguientes objetivos principales: a) Elaborar proyectos artísticos en áreas de interés común. b) Generar espacios de

\footnotetext{
9 "[L]a mémoire n’est plus alors [...] que la réflexion de soi sur soi étalée dans le temps;"
} 
debate y reflexión sobre la historia compartida y los proyectos comunes como naciones latinoamericanas. c) Organizar actos conjuntos conmemorativos y celebraciones con motivo de los Bicentenarios. d) Elaborar publicaciones conjuntas. e) Coordinar actividades culturales relativas a los Bicentenarios que involucren la participación de las provincias, estados o regiones de los respectivos países.

Sin embargo, para alcanzar estos objetivos, las semejanzas históricas son menos determinantes que las grandes diferencias políticas presentes en la región. Carmen Bohórquez, miembro de la Comisión Presidencial para la Celebración del Bicentenario de la Independencia de Venezuela, aclara en una entrevista:

Existe un grupo Bicentenario donde hay varios países latinoamericanos representados, indudablemente que allí las diferencias políticas se manifiestan hasta en la manera como se va a celebrar los bicentenarios. Están países con gobiernos que son de derecha, e incluso hay algunos que tienen una visión casi comercial del asunto, que lo ven como algo para turistas o como obtener más ingresos. Y otros, los que estamos más políticamente implicados en procesos revolucionarios, nosotros lo vemos como la ocasión propicia para profundizar la batalla de ideas. (Gómez 2010)

Otro motivo de confrontaciones dentro del Grupo es la participación del Estado español, como demuestra una entrevista al presidente del Centro $\mathrm{Na}$ cional de Historia venezolano, Arístides Medina, que se mosquea de que algunos países, pero particularmente España, tengan un interés especial en que el nombre Simón Bolívar se borre de la memoria de los pueblos.

Desde España nos están proponiendo una Conmemoración del Bicentenario como una acción generada por ellos, para hacer ver que la Independencia de América se produjo por la vocación democrática de esa Nación. (Uzcatia 2009: párr. 7)

De la misma manera, la ya arriba citada Carmen Bohórquez sostiene en otra entrevista que "España pretende dar vuelta a la historia de tal manera que pueda aparecer como si en realidad hubiera sido la verdadera inspiradora de nuestras independencias. Ya lo hizo con la celebración del V Centenario del Descubrimiento de América en 1992 y lo repite ahora" (Montoya 2009, párr. 2). Esta tesis de repetición y de paralelas entre las dos conmemoraciones suena lógica, pero ¿hasta qué punto influyen los intereses del Estado español en las políticas de memoria latinoamericanas? ¿Es la implicación española un obstáculo para el proceso de integración regional?

Lo cierto es que la colaboración dentro del Grupo Bicentenario desde su creación en 2007 hasta el 2011 no se llevó a cabo como planificado. El Acta
Las políticas públicas de memoria y la integración latinoamericana: el Grupo Bicentenario

Georg T. A. Krizmanics 
América Latina: cambios a nivel regional y en su inserción internacional de la IV Reunión del Grupo Bicentenario (2009: 7) indica la alternancia de la Secretaría Pro Témpore (SPT) entre 2009 y 2010. Sin embargo, los mandatos de Venezuela, previstos durante enero y junio de 2010, seguidos por Colombia hasta finales del mismo año, nunca se pusieron en práctica. De hecho, no se encuentra ningún índice que afirme el traspaso de la SPT de México a finales de 2009 a Venezuela. El poco interés por parte de Venezuela de reivindicar su mandato se explica, entre otras cosas, por la crisis bilateral duradera entre Colombia y este país y sus prioridades poco compatibles con el mismo Grupo Bicentenario. Una muestra de ello es la constitución del Grupo ALBA para la Conmemoración del Bicentenario del Inicio de la Revolución de Independencia en Nuestra América el 24 de junio de 2009..$^{10}$

Si comparamos el Grupo Bicentenario con el Grupo ALBA para la Conmemoración del Bicentenario ¿cuáles son las principales diferencias?

Lo más llamativo es el periodo de tiempo divergente. El primer suceso que consta en la línea de tiempo, disponible en la página del Grupo Bicentenario, es la Independencia de Haití en 1804 y, el último, la Declaración de Independencia de la Provincia Oriental (Uruguay) en 1825. Fuera de esta mención de Haití y su Declaración de Independencia la relevancia del hecho es más bien marginal y no cobra importancia explícita en ningún momento del ciclo conmemorativo descrito. Solamente hay dos datos más que hacen referencia al rol jugado por Haití durante los procesos de independencia de América Latina y los dos se encuentran en el Acta de la IV Reunión del Grupo Bicentenario (2009: 1-7). Ahí consta que Ecuador realizó durante la reunión precisiones históricas en este sentido y que Argentina hizo "énfasis en la necesidad de reivindicar el rol jugado por Haití en las gestas independentistas”. El Acta indica, además, que se adjunta, como Anexo IV, la Declaración referente a Haití, que en un principio estaba accesible en la misma página del grupo y que luego desapareció por completo de la misma. El autor accedió a esta "Declaración del Grupo Bicentenario sobre el Rol de la República de Haití en los Procesos de Independencia Latinoamericanos" por última vez el 20 de mayo de 2009. Del hecho de que esta Declaración verdaderamente existe da prueba únicamente el Número 31.692/Año CXVII del Boletín Oficial de la República Argentina que data del 13 de julio de 2009. El Boletín reproduce el Documento de la Reunión del Grupo Bicentenario incluyendo la Declaración sobre Haití que contiene el texto siguiente:

Durante el presente año las naciones que conforman el Grupo Bicentenario darán comienzo al ciclo de conmemoraciones de los bicentenarios de los procesos de independencia en América Latina.

El Grupo Bicentenario recuerda que esta primera gesta por la libertad comenzó en el año 1804, en Haití, cuando un valeroso grupo de insurgentes puso

10 Para el Acta Constitutiva y demás documentos véase: http://www.alba-tcp.org, consulta: 31.01.2013. 
fin al yugo colonial y al oprobio de la esclavitud, abriendo paso, de esta manera, a los sucesivos procesos de independencia en nuestra región. ${ }^{11}$

Este párrafo me lleva a varias conclusiones: Primero, recordar en una declaración que la primera gesta por la libertad comenzó en 1804 en Haití le da a todo el proceso un aspecto genuinamente latinoamericano. Esto evita el protagonismo de otros antecedentes a menudo citados, tales como la independencia de las Trece Colonias norteamericanas en 1776, la revolución Francesa en 1789 y la crisis en la península ibérica por la invasión francesa de Napoleón en 1808. Previa invitación, España formalizó su participación en el grupo el 23 de febrero de 2009, lo que posiblemente desató la iniciativa de la Declaración. Segundo, ya que el grupo no invita al Estado haitiano a participar como miembro del Grupo Bicentenario en las conmemoraciones, da la impresión de utilizarlo, sobre todo, como comodín para propios fines. Haciendo referencia a Haití, sin que este país tenga voz o voto en la organización de las conmemoraciones, puede calmar una posible rivalidad sobre la pregunta quién fue el primero en dar la primera gesta libertaria. Tercero, en un contexto de historia transatlántico, hacer referencia a la Independencia de Haití se puede interpretar como un intento de establecer una narrativa de "contra historia", si se tiene en cuenta que las circunstancias de la Independencia de Haití han sido silenciadas, en gran medida hasta hoy, en comparación con la atención que han recibido los antecedentes de los demás movimientos independentistas arriba mencionados.

Es curioso que Hugo Chávez y su gobierno se han presentado como los defensores de una contra historia, tanto a nivel nacional como a nivel regional, cuando son ellos quienes representan el poder oficial que como tal define la historia oficial. En el Foro "Ideas de la Independencia", realizado bajo la responsabilidad del Ministerio venezolano del Poder Popular para la Cultura, el profesor venezolano Mario Sanoja deja claro que la característica fundamental de la presente conmemoración de los 200 años de emancipación es buscar "construir un nuevo discurso histórico que explique ese proceso de independencia en los términos de la revolución socialista venezolano." De este modo, se pretende rescatar "un pueblo invisibilizado en la historia oficial" y "destapar la historia que durante siglos fue minimizada e inclusive, ocultada”. (Sulbarán 2010: párr. 1)

De acuerdo a estas aspiraciones, los "Hitos del Bicentenario de la Independencia de Nuestra América”, según los dirigentes de los Estados miembros de la Alianza Bolivariana para los Pueblos de Nuestra América - Tratado de Comercio de los Pueblos (ALBA-TCP), difieren en algunos puntos de la línea de tiempo elaborada por el Grupo Bicentenario. ${ }^{12}$ Primero, el periodo de tiempo abarca 50 años (1780-1830), empezando por la Sublevación de los hermanos Katari en el

\footnotetext{
11 Véase página 2 del Boletín

12 Véase: http://www.alba-tcp.org/public/documents/pdf/hitos_del_bicentenario.pdf, consulta: 31.01.2013.
}

Las políticas públicas de memoria y la integración latinoamericana: el Grupo Bicentenario

Georg T. A. Krizmanics 
América Latina: cambios a nivel regional y en su inserción internacional
Alto Perú (hoy Bolivia) y terminando por la Muerte de Simón Bolívar. Las referencias a la Revolución de Haití son extensivas, pero este país tampoco cobra un mayor protagonismo real en los eventos del ciclo de las conmemoraciones. En cambio, los sucesos en la península ibérica, que sí constan en la línea de tiempo del Grupo Bicentenario, se dejan completamente fuera. Segundo, la agenda perseguida por el ALBA-TCP sobrepasa la mera promoción de la celebración de las diversas efemérides de cada uno de los países miembros - propuesta central del Grupo Bicentenario - y persigue con el plan de trabajo y acción metas concretas que dan prueba de un proyecto político explícito de memoria y de identidad.

El cronograma de cumplimiento de dicha agenda de trabajo puede ir aparejada con determinadas fechas históricas, de manera tal que el cumplimiento de la meta fijada y la conmemoración de determinada fecha bicentenaria, se conviertan en sí mismas en símbolo de la continuidad de la lucha y en resignificación de una historia que hasta el momento ha estado al servicio de las élites dominantes. ${ }^{13}$

El liderazgo en todas esas tareas Chávez se lo atribuye claramente al pueblo venezolano y a sus representantes, ya que "a nosotros los venezolanos, los hijos de Bolívar, de Josefa Camejo, de Guaicaipuro, de Miranda, de nuevo la historia nos ha puesto a la vanguardia de las luchas en este continente. Asumamos, pues, nuestro desafío. Marchemos a la vanguardia de los cambios en América Latina y el Caribe." (Chávez Frías 2010: 27)

Estas pretensiones pueden haber influido en el deterioro de las relaciones en el seno del Grupo Bicentenario a partir de finales del año 2009. Ello se hizo palpable, por ejemplo, en la disponibilidad de la página web del grupo que en los últimos dos meses de 2010 y los primeros dos meses de 2011 osciló entre vida y muerte. Había días en los que no funcionaba, otros en los que reapareció, como si no hubiera sucedido nada, y otros más cuando solamente se cargó el diseño de fondo de la misma, sin posibilidades de navegar ni acceder a los contenidos anteriormente disponibles. Fuese cual fuese la razón para este fenómeno, el funcionamiento de la página volvió a su normalidad anterior a mitades de 2011. No obstante, volvió a desaparecer su contenido pocos meses después y así sigue actualmente. Lo único que aparece cuando uno visita la página son las banderas de los países que forman parte del Grupo Bicentenario.

Un fenómeno parecido experimentaron algunas páginas que lanzaron los gobiernos nacionales, miembros del Grupo Bicentenario, destinadas exclusivamente a la conmemoración nacional respectiva. La página de Bolivia, por

${ }^{13}$ Véase: http://www.alba-tcp.org/contenido/plan-de-trabajo-grupo-alba-bicentenario, consulta: 6.02.2011. La versión en español del plan de trabajo ya no es accesible, la versión en inglés, sin embargo, sí: http://www.alba-tcp.org/en/contenido/work-plan-bicentennial-alba-group-bicentennial-goals, consulta: 31.01.2013. 
ejemplo, desapareció poco después de las conmemoraciones en el año 2009, la de Ecuador dejó de existir en el segundo semestre de 2010, a pesar de que el presidente Rafael Correa decretó en 2008 que "la República de Ecuador se apresta a conmemorar el Bicentenario de las Luchas Libertarias de 1809 a 1812." (Registro Oficial de Ecuador 325/1023/punto 1) No quedan nada claro los motivos que llevan a esta gestión nebulosa de las páginas.

\section{Reflexiones sobre la percepción de los bicentenarios entre los ciudadanos latinoamericanos}

La aparición inflacionaria de temas relacionados a los bicentenarios en los ámbitos de la vida pública de América Latina y el Caribe indujo a los investigadores de Latinobarómetro a incluir en la edición de 2009 preguntas al respecto. ¿Entonces, cuál es la percepción de los ciudadanos al respecto de las conmemoraciones bicentenarias?

El informe anual incluye datos que se hicieron constar en 16 países hispanoamericanos, repartidos en dos grupos. El primero abarca los Estados que conmemoran sus bicentenarios entre 2009 y 2012 y el segundo a los que lo hacen entre 2021 y 2025. Además, se consideraron la República Dominicana, la cual se independizó de Haití en 1844, y Brasil que se declaró independiente de Portugal en 1822 (Latinobarómetro 2009: 111). Sin embargo, los investigadores no dan ninguna importancia a Haití, lo que se explica por la definición territorial de América Latina que subyace al sondeo (Latinobarómetro 2009: 2). Además, cabe precisar que este agrupamiento no distingue entre el comienzo del proceso de independencia y la independencia formal de los Estados. Solamente mesura la importancia que los interrogados atribuyen a los sucesos en su conjunto.

Los datos indican, por un lado, que el conocimiento de los latinoamericanos sobre la cuestión de quién se independizó de su país correspondiente - España, Portugal o Haití - es más bien bajo. ${ }^{14}$ Solamente el $43 \%$ de los/las interrogados/as en los Estados hispanoamericanos responde correctamente, el mismo porcentaje que en Brasil, pero menos que en República Dominicana, donde el 57\% da una respuesta correcta. Los autores del estudio explican estos valores con el bajo nivel promedio de educación después de siete años de escolarización (Latinobarómetro 2009: 110). No obstante, los datos documentan que el 57\% de los interrogados en toda América Latina atribuyen a los bicentenarios una importancia significativa, como se desprende de la segunda pregunta (Latinobarómetro 2009: 111 y s.). ${ }^{15}$ La parte superior de la

\footnotetext{
${ }^{14}$ La pregunta que se hizo fue: "Próximamente se cumplen 200 años de la independencia en varios países, queremos saber ¿De quién se independizó (país)?”

15 La pregunta que se hizo fue: “¿Cuán significativo es para Ud. el Bicentenario de la independencia: 'Muy significativo (1)'; 'Bastante significativo (2)'; 'Algo significativo (3)'; o 'No significa nada (4)' para usted?”.
}

Las políticas públicas de memoria y la integración latinoamericana: el Grupo Bicentenario

Georg T. A. Krizmanics 
América Latina: cambios a nivel regional y en su inserción internacional escala la ocupa Brasil con el 77\%. De los miembros del Grupo Bicentenario Venezuela (63\%), México (61\%), El Salvador y Chile (ambos 59\%) y Bolivia $(58 \%)$ se sitúan por encima del promedio. Por debajo aparecen Ecuador (52\%), Argentina (51\%), Paraguay (48\%) y Colombia (36\%), siendo este país al mismo tiempo el último de la cola. En resumen, viendo el conjunto de los países miembros del Grupo Bicentenario, la mayoría de los interrogados atribuye a los bicentenarios una importancia significativa, teniendo en cuenta que en siete de los nueve países más del $50 \%$ de los interrogados se pronunció en este sentido.

Con referencia a las voces que critican la participación de España en las conmemoraciones bicentenarias, el informe del Latinobarómetro también ofrece datos instructivos. ${ }^{16}$ En total, el 57\% de los interrogados en América Latina indican que la influencia española en la región "desde el descubrimiento de América" ha sido positiva. Lidera la cola la República Dominicana (73\%), siendo Perú (43\%) el país que se encuentra al lado opuesto de la escala. Llama la atención que entre los diez países sudamericanos solamente tres: Venezuela (64\%), Uruguay (61\%) y Chile (59\%), superen el promedio del $57 \%$ y que en Venezuela, teniendo en cuenta la situación política actual, se haya dado el porcentaje más alto. Los porcentajes obtenidos en todos los demás Estados miembros del ALBA se encuentran por debajo del promedio. Los encuestados en Perú (43\%) son los que peor ven "la influencia de España desde el descubrimiento de América”, seguidos por, y superados solamente por un punto, los de Ecuador (44\%). Entre el promedio y la imagen más negativa de España se sitúan Nicaragua (49\%) y Bolivia (52\%).

Lastimosamente, este estudio sobre la percepción de los ciudadanos en cuanto a las conmemoraciones bicentenarias se hizo nada más que una sola vez. Podría haber sido realmente interesante poder contar con datos comparables desde 2009 hasta 2012.

\section{Conclusiones}

Dado lo anteriormente expresado, se puede hablar de un fracaso del Grupo Bicentenario en el que se refleja, de alguna manera, el estado de la integración regional. En vez de tratar de encontrar imperativamente soluciones a los problemas que se presentaron a lo largo de la existencia de este organismo, algunos países miembros prefirieron abandonarlo, otros se decidieron por crear una iniciativa parecida, pero no igual y, sobre todo, de menos transcendencia. El Grupo Bicentenario, como plataforma de diálogo, podría haber sido aprovechado mucho mejor para trabajar y disminuir varios puntos de fricción entre los Estados miembros: las diferencias ideológicas entre algunos de estos

${ }^{16}$ La pregunta que se hizo fue: “ Históricamente y considerando todo, cómo valora la influencia que España ha tenido en (país) desde el descubrimiento de América?” 
gobiernos, por un lado, y las fricciones en cuanto a la historia oficial sostenida por España y los gobiernos latinoamericanos, por otro.

Carlos Malamud (2011: 25) resalta en un primer balance de los bicentenarios latinoamericanos varias razones que tratan de explicar los impedimentos de promover una conmemoración conjunta y de alcanzar una proyección internacional:

(1) la gran fractura existente en la región y los conflictos bilaterales [...]; (2) la politización de los festejos [...]; (3) los intentos de falsificación de las historias nacionales y de la latinoamericana; (4) el escaso presupuesto invertido; (5) la improvisación y la falta de planificación; (6) el bajo grado de conocimiento por parte de las sociedades latinoamericanas de lo que se festejaba; y (7) [...] la trivialización y mercantilización del concepto o la marca bicentenario.

Este balance es, al mismo tiempo, un balance del estado de la integración en la región. La integración sufre con los conflictos bilaterales; la integración es politizada, en general improvisada y poco planificada; no cuenta con los recursos necesarios para llevarla a un nivel más elevado y de mayor cohesión. La integración es trivializada.

\section{Bibliografía}

ALBA (2004), Declaración conjunta entre el presidente de la República Bolivariana de Venezuela y el presidente del Consejo de Estado de la República de Cuba para la creación del $A L B A$, en La Habana, Cuba, del 14 de diciembre.

ALBA-TCP (2010), Manifiesto Bicentenario de Caracas, Declaración Final de la IX Cumbre del ALBA, del 19 de abril.

Altmann J., Rojas Aravena F. (2008), Introducción. América Latina: Dilemas de la Integración, en: Las paradojas de la integración en América Latina y el Caribe, J.: Altmann, F. Rojas Aravena (ed.), Fundación Carolina y Siglo XXI de España Editores S. A., Madrid.

Boeckh A. (2005), 'Sozialismus des 21. Jahrhunderts'? Das venezolanische Reformprojekt von Hugo Chávez, en: Jahrbuch Lateinamerika 29: Neue Optionen lateinamerikanischer Politik. Analysen und Berichte, K. Gabbert et al. (ed.), Verlag Westphälisches Dampfboot, Münster.

Boletín Oficial de la República Argentina (2009), no 31.692, año CXVII del 13 de julio, disponible en: http://www.boletinoficial.gov.ar, consulta: 31.01.2013.

Bolívar S. [1819] (2008), Discurso de Angostura, Ministerio del Poder Popular parala Comunicación y la Información, Caracas, disponible en: http://www.minci.gob.ve, consulta: 31.01.2013.

Bourdieu P. (1993), Esprits d'Etat, en: "Actes de la recherche en sciences sociales", doi: 10.3406/arss.1993.3040.

Calderón Hinojosa F. (2010), Discurso en la Ceremonia de Entrega de la Secretaría Pro Témpore del Grupo de Río, en: Cumbre de la Unidad de América Latina y el Caribe Quintana Roo, México, G. M. Santos Villarreal (ed.), disponible en: http://www.diputados.gob.mx/ cedia/sia/spe/SPE-CI-A-03-10.pdf, consulta: 31.01.2013.

Chávez Frías H. (2010), Rumbo a la independencia plena. Mensaje anual del presidente Hugo Chávez Frías a la nación. Sesión especial de la Asamblea Nacional con motivo del mensaje
Las políticas públicas de memoria y la integración latinoamericana: el Grupo Bicentenario Georg T. A. Krizmanics 
América Latina: cambios a nivel regional y en su inserción internacional anual del Comandante Presidente de la República Bolivariana de Venezuela, Hugo Chávez Frías, Palacio Federal Legislativo Caracas, 15 de enero, disponible en: http://www.minci. gob.ve, consulta: 31.01 .2013 .

CALC (2008), Declaración de Salvador, Cumbre de América Latina y el Caribe sobre Integración y Desarrollo, Bahía, Brasil, del 17 de diciembre de 2008, disponible en: http:// www.sre.gob.mx/cumbredelaunidad/calc.htm, consulta: 31.01.2013.

Gabbert K. (2008), 'Ein Held für alle Zwecke’. Hugo Chávez und andere Wiedergänger von Simón Bolívar, en: Erinnerung macht gegenwart. Jahrbuch Lateinamerika. Analysen und Berichte, A. Huffschmied, M. Krämer, K. Gabbert, W. Gabbert, U. Goedeking, A. Nana Heidhues, T. Schmid, Ch. Schulte, R. Stanley (ed.), Verlag Westphälisches Dampfboot, Münster.

Garavaglia J. C. (2003), La apoteósis del Leviathán: El estado en Buenos Aires durante la primera mitad del siglo XIX, "Latin American Research Review", no 38.

García-Belaunde J. A. (2000), El sueño de Bolívar: De la Federación de los Andes a la Comunidad Andina, disponible en: http://www.comunidadandina.org, consulta: 31.01.2013.

Gómez Y. (2010), Doscientos años después de la Independencia de América, tenemos al pueblo en las calles diciendo cuál es el camino, "Revista Mariátegui", disponible en: http:// carmenbohorquez.psuv.org.ve, consulta: 6.02.2011.

Grupo Bicentenario (2007a), Carta de Intención de los Ministros de Cultura relativa a la realización de actividades conjuntas para la Conmemoración de los Bicentenarios, Valparaíso, Chile, del 26 de julio, disponible en: http://wwwgrupobicentenario.org, consulta: 15.06.2009.

Grupo Bicentenario (2007b), Acta Primera Reunión, Santiago de Chile, del 5 de diciembre, disponible en: http://wwwgrupobicentenario.org, consulta: 15.06.2009.

Grupo Bicentenario (2009), Acta IV reunión, Buenos Aires, Argentina, del 28 al 29 de abril, disponible en: http://wwwgrupobicentenario.org, consulta: 5.05.2009.

Gudynas E. (2006), Los fantasmas de la integración regional, "Revista del Sur", no 166, disponible en: http://www.integracionsur.com, consulta: 31.01.2013.

Harwich N (2003), Un héroe para todas las causas: Bolívar en la historiografía, "Iberoamericana", vol. III, no 10.

Kaller-Dietrich M. (2006), Las Américas im Vergleich - Good Neighbors im Schatten der 'Zweiten Conquista', en: Nord-Süd-Beziehungen. Kolonialismen und Ansätze zu ihrer Überwindung, B. Englert et al. (ed.), mandelbaum Verlag, Wien.

Lamore J. (2007), José Martí. La liberté de Cuba et de l'Amérique latine, Ellipses Édition Marketing S.A., Paris.

Latinobarómetro Corporación (2009), Informe 2009, Corporación Latinobarómetro, Santiago de Chile, disponible en: http://www.latinobarómetro.org, consulta: 31.01.2013.

Malamud C. (2008), La integración que no acaba de llegar, "Revista de libros de la Fundación Caja Madrid", no 143, disponible en: http://www.revistadelibros.com, consulta: 31.01.2013.

Malamud C. (2009), La crisis de la integración se juega en casa, "Nueva Sociedad", no 219, disponible en: http://www.nuso.org, consulta: 31.01.2013.

Malamud C. (2011), Un balance de los bicentenarios latinoamericanos: de la euforia al ensimismamiento, Documento de Trabajo 1/2011 del Real Instituto Elcano, disponible en: http://www.realinstitutoelcano.org, consulta: 31.01.2013.

Martí J. (2005a) [1889], Carta al director de La Nación del 2 de noviembre de 1889, en: J. Martí, Nuestra América, Fundación Biblioteca Ayacucho, Caracas. 
Martí J. (2005b) [1889], Discurso Pronunciado ante la Sociedad Literaria Hispanoamericana ('Madre América') el 19 de diciembre de 1889, en: J. Martí, Nuestra América. Fundación Biblioteca Ayacucho, Caracas.

Martí J. (2005c) [1891], Nuestra América, en: J. Martí, Nuestra América, Fundación Biblioteca Ayacucho, Caracas.

Martí J. (2005d) [1893], Simón Bolívar. Discurso pronunciado en la velada de la Sociedad Literaria Hispanoamericana en honor de Simón Bolívar el 28 de octubre de 1893, en: J. Martí, Nuestra América, Fundación Biblioteca Ayacucho, Caracas.

Ministerio del Poder Popular para Relaciones Exteriores de la República Bolivariana de Venezuela (2011), Comunicado. Gobiernos de América Latina y el Caribe estudian nueva fecha para celebrar la CALC, disponible en: http://www.mre.gob.ve, consulta: 8.08.2011.

Montoya R. (2009), España pretende apropiarse de los festejos del bicentenario de nuestras independencias. Entrevista a Carmen Bohórquez, "Periódico Diagonal", del 17 de noviembre, disponible en: http://www.diagonalperiodico.net, consulta: 31.01.2013.

Palacios G., Moraga F. (2003), La independencia y el comienzo de los regímenes representativos, Editorial Síntesis, S.A., Madrid.

Pimenta J. P. G. (2007), Brasil y las revoluciones de Hispanoamérica (1808-1822), en: J. P. G. Pimenta, Brasil y las independencias de Hispanoamérica, Publicaciones de la Universidad Jaume I, Castelló de la Plana.

Prensa Presidencial Venezolana (2011), Presidente Chávez encabezó desde Miraflores actos del Bicentenario, Disponible en: http://minci.gob.ve, consulta: 31.05.2012.

Ramonet I. (2008), Fidel Castro. Biografía a dos voces, DeBOLS!LLO, Barcelona.

Registro Oficial de Ecuador (2008), Decreto $N^{o} 1023$, del 15 de abril, por el que se constituye el Comité Presidencial del Bicentenario, cuya misión será planificar y coordinar la ejecución del Programa de Conmemoraciones del Bicentenario entre 2008 y 2012, publicado el 28 de abril, disponible en: http://www.derechoecuador.com, consulta: 31.01.2013.

Ricœur P. (2000), Lécriture de l'histoire et la représentation du passé, "Annales. Histoire, Sciences Sociales", 55e année, no 4.

Rinke S. (2010), Revolutionen in Lateinamerika. Wege in die Unabhängigkeit 1760-1830, Verlag C. H. Beck oHG, München.

Rodríguez O. (2011), Cancilleres avanzaremos para consolidar el concepto de la Comunidad de Estados Latinoamericanos y del Caribe. Nicolás Maduro recibe a homólogos, "Venezolana de Televisión", disponible en: http://www.abrebrecha.com, consulta: 31.01. 2013.

Roig A. A. (2007), Necesidad de una segunda independencia, en: América Latina hacia su segunda independencia. Memoria y autoafirmación, H. E. Biagini, A. A. Roig Aguilar (ed.), Altea, Taurus, Alfaguara, Buenos Aires, disponible en: http://www.ensayistas.org/critica/ generales/biagini/segunda-independencia.pdf, consulta: 31.01.2013.

Sandino Augusto C. (1982) [1929], Plan zur Verwirklichung von Bolívars höchstem Traum, en: Der lange Kampf Lateinamerikas. Texte und Dokumente von José Martí bis Salvador Allende, Á. Rama (ed.), Suhrkamp Verlag, Frankfurt am Main.

Sandner G. (2001), Hegemonie und Erinnerung: Zur Konzeption von Geschichts - und Vergangenheitspolitik, "ÖZZ”, no 30.

Sotillo J. Á. (2010), Prólogo. La cooperación Sur-Sur y su irrupción en un mundo en transformación, en: La cooperación Sur-Sur en Latinoamérica. Utopía y Realidad, B. Ayllón Pino, J. Surasky (coord.), Catarata, Madrid.
Las políticas públicas de memoria y la integración latinoamericana: el Grupo Bicentenario

Georg T. A. Krizmanics 
América Latina: cambios a nivel regional y en su inserción internacional
Sulbarán B. (2010), Mario Sanjona: 'Estamos buscando construir un nuevo discurso histórico', "Comunicado de prensa MinCI", del 18 de mayo, disponible en: http://www.minci.gob.ve, consulta: 31.01.2013.

Ugarte M. (1922), El ideal de los hombres de la Independencia. Al llegar a Bogotá, el 20 de septiembre de 1912, en: M. Ugarte, Mi campaña hispanoamericana, Cervantes, Barcelona.

UNASUR (2008), Tratado Constitutivo de la Unión de Naciones Suramericanas, Brasilia, del 23 de mayo, disponible en: http://www.comunidadandina.org, consulta: 31.01.2013.

Uzcatia D. (2009), Bicentenario y el Socialismo Bolivariano consolidan la verdadera Independencia de Venezuela. Entrevista a Arístides Medina, "Comunicado de prensa MinCI", del 1 de junio, disponible en: http://www.minci.gob.ve, consulta: 31.01.2013.

Wodak R., de Cillia R. (2007), Commemorating the past: the discursive construction of official narratives about the 'Rebirth of the Second Austrian Republic', "Discourse \& Communication", vol. 1, no 3.

Michael Z. (2009), Simón Bolivar in Geschichte, Mythos und Kult, en: Vielstimmige Vergangenheiten - Geschichtspolitik in Lateinamerika. jAtención! Jahrbuch des Österreichischen Lateinamerika-Instituts, B. Molden, D. Mayer (ed.), Lit Verlag, Wien-Berlin. 